\title{
Medical bodies secure 'safe' data network
}

London. The British government has agreed in principle to set up a secure network for the electronic transmission of patient records. The move follows concern from the medical profession that patient confidentiality may be at risk from the growing use of 'unsecure' channels such as facsimile transmissions and, in particular, the Internet.

Last week, officials from the British Medical Association, accompanied by the heads of the various royal colleges - Britain's professional medical bodies - put the case to Stephen Dorrell, the Secretary of State for Health, for a 'secure' medical information network to handle information such as the data produced by pathology laboratories, or the transfer of medical records when patients register with a new doctor.

Dorrell is understood to have agreed in principle to their proposal, although details have yet to be worked out. Potential providers of such a network - which include British Telecom - are also believed to have been approached, and are understood to have expressed their willingness to collaborate on the project.

Several issues, however, will need to be addressed before any encrypted network goes on-line. For example, it needs to be decided who will regulate, provide access to, and monitor security on the network. Other decisions concern who should have what level of access to information on the network, as well as the criteria for allowing entry to an individ-

ual or organization to gain entry.

The meeting between Dorrell and doctors' representatives was held in parallel with a conference on the encryption of medical records which took place at the BMA's headquar- Winston: medicine can ters in London last

week. The BMA is expected to make a public announcement about its proposals in the near future.

The government's move coincides with a bid by the opposition Labour Party to use the potential benefits of the information

\section{HIV compensation package under offer}

Tokyo. Over 200 Japanese haemophiliacs infected with HIV by contaminated blood products will each receive $¥ 45$ million (US $\$ 450,000$ ) in compensation from the government and pharmaceutical companies if a compromise proposal announced last week by the Tokyo and Osaka district courts is accepted.

The recommendation follows years of litigation that began in 1989 when a group of infected haemophiliacs brought the first 'HIV suit' claiming that five companies that had imported the blood products into Japan - Green Cross Corporation, the Chemo Sero Therapeutic Research Institute, Baxter Ltd, Bayer Yakuhin Ltd and Nippon Zoki Pharmaceutical Company - as well as the government that approved their sale, were guilty of negligence.

By agreeing to the plan, the government would avoid a possible court ruling that it was negligent in allowing contaminated blood products to be marketed in Japan for several years after heat-treated products were available. The government's acceptance of the plan would not set a legal precedent. But Shinichi Tokunaga, a lawyer representing the plaintiffs in Osaka, says that it would strengthen the hand of future litigants.

The haemophiliacs' group alleges that the government and the companies allowed potentially infected products to be used, despite knowing they might be dangerous. As in France, where government officials have already been jailed because they delayed introduction of heattreated products (see Nature 375, 349; 1995), Japan did not allow the use of coagulants treated with heat to kill HIV and other viruses until 1985, more than two years after they were approved for use in the United States.

In June 1983, a division of the Ministry of Health and Welfare's pharmaceutical affairs bureau set up an AIDS study group, headed by Takeshi Abe of Teikyo University, to advise on blood products policy. This advised the government to withhold approval of heat-treated products until clinical trials were completed in Japan. In the ensuing two years, up to 2,000 haemophiliacs were infected.

The settlement proposal calls for each plaintiff to be paid $¥ 45$ million, with the government meeting 40 per cent of the cost. The plaintiffs had requested $¥ 115$ million for each plaintiff, as well as apologies from the government and the companies. Toshihiro Suzuki, leading counsel for the plaintiffs in Tokyo, promised to continue to fight until they received an unequivocal apology from the ministry, which is refusing to speculate on whether it will accept the plan, or offer compensation to all those infected.

Steven Barker superhighway for providing medical services to justify its agreement to allow this highway to be built by British Telecom.

Speaking at the party's annual conference last week, Tony Blair, the Labour leader, singled out for special mention a proposal that the superhighway could be used to reestablish the importance of centres of medical excellence. The activities of these centres, his supporters claim, have been weakened by the 'internal market' created by the conservative government within the National Health Service.

The proposal had been put to Blair by Robert Winston, professor of fertility studies at Hammersmith Hospital in London, a leading pioneer of in vitro fertilization techniques (and, according to some press reports, a likely Labour nominee for a 'working peerage' in the House of Lords).

Winston claims that the internal market has been a "disaster" for centres of excellence (such as Hammersmith Hospital). By encouraging local health 'fundholders' to shop around for the most economic treatment, he says, it has discouraged such fundholders from sending patients to major research and teaching hospitals, where costs are inevitably higher.

The result, says Winston, not only makes it more difficult for such hospitals to attract patients, but may also "reduce our ability to train medical students, as we are not able to put the same quantity of clinical material in front of them". The answer, he adds, is to increase support for regional centres of excellence, and to use the superhighway to connect them with local general practitioners and other medical services.

Winston argues that such enhanced regional centres, using the superhighway to transmit "any material that can be digitized from doctor to doctor", would be in a position to take on a key strategic role in improving general standards of treatment and medical education.

"I think that it would be a very good thing for medicine, but it needs the stimulus of a government prepared to do things that are currently held back by the philosophy of the internal market," says Winston.

- Britain's former Archbishop of York the second-most senior Church of England official - Lord Habgood, has criticized the Internet as a medium in which "truths and principles" are being replaced by an "endless succession of human opinions".

Lord Habgood, a trained biologist, who retired as archbishop in the summer, said in the annual Priestland Memorial Lecture that the volume of information on the Internet was in danger of disorienting people.

"The accumulated wisdom of past generations," he said, is being replaced by a "mad scramble for personal fulfilment". 